$17^{\circ}$ ERGODESIGN \& USIHC 2019

PUC-Rio, 11 a 13 de dezembro

Rio de Janeiro, RJ, Brasil $17^{\circ}$ Ergodesign - Congresso Internacional de Ergonomia e Usabilidade de Interfaces Humano Tecnológica: Produto, Informações Ambientes Construídos e Transporte

$17^{\circ}$ USIHC - Congresso Internacional de Ergonomia e Usabilidade

de Interfaces Humano Computador

\title{
Equipamentos de ginástica - satisfação e caracterização dos usuários
}

\author{
Fitness equipment - satisfaction and characterization of the users
}

\author{
SILVA, Renan Sena de Castro \\ Universidade Federal de Campina Grande, Bacharel \\ renan_sena_castro@hotmail.com \\ VELOSO, Isis Tatiane de Barros Macêdo \\ Universidade Federal de Campina Grande, Dra. \\ isistmacedo@gmail.com
}

\section{RESUMO}

A população idosa no mundo está melhorando cada vez mais sua qualidade de vida através do avanço da medicina. Para uma boa qualidade de vida, a atividade física é essencial para a manutenção e preservação da capacidade funcional dos idosos, trazendo ganhos físicos e mentais para a saúde. Porém, para atingir tais objetivos é necessário a existência de espaços que contemplem também o público idoso. Por volta de 2005 começaram a ser instaladas algumas academias de ginástica ao ar livre, destinadas à prática de exercícios físicos, de uso coletivo e gratuito para a população. O objetivo deste artigo é caracterizar o usuário idoso, bem como verificar sua satisfação sob o uso dos equipamentos de ginástica. Foram realizados testes com usuários, divididos em duas partes: a primeira para caracterização, verificando 0 perfil social, e a segunda para análise da satisfação, observando preferências e tendências de usabilidade para com os equipamentos. A maioria dos usuários é alfabetizada, aposentada, e todos são idosos ativos. Apresentam preferência por alguns equipamentos específicos, porém os usuários tem de forma geral, uma satisfação positiva sobre o grupo de equipamentos, pois eles se apresentam intuitivos, seguros, confortáveis e não exigem grande intensidade na realização dos exercícios.

Palavras chave: design, ergonomia, usabilidade, satisfação do usuário, equipamentos de ginástica.

\begin{abstract}
The elderly population in the world is increasingly improving their quality of life through the advancement of medicine. For a good quality of life, physical activity is essential for maintaining and preserving the functional capacity of the elderly, bringing physical and mental health gains. However, to achieve such goals, it is necessary to have spaces that also include the elderly public. Around 2005 began to be installed some outdoor fitness centers, for the practice of physical exercise, for free and for the population. The purpose of this article is to characterize the elderly user, as well as to verify their satisfaction under the use of exercise equipment. Tests were performed with users divided into two parts, the first for characterization, verifying the social profile, and the second for satisfaction analysis, observing preferences and usability trends with the equipment. Most users are literate, retired, and all are active seniors. They have a preference for some specific equipment, but users have totally positive satisfaction about the equipment group, as they are intuitive, safe, comfortable and do not require great intensity in the exercises.
\end{abstract}




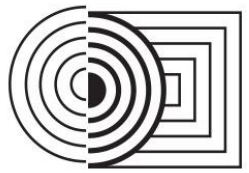

\section{$17^{\circ}$ ERGODESIGN \& USIHC 2019}

PUC-Rio, 11 a 13 de dezembro

Rio de Janeiro, RJ, Brasil $17^{\circ}$ Ergodesign - Congresso Internacional de Ergonomia e Usabilidade de Interfaces Humano Tecnológica: Produto, Informações Ambientes Construídos e Transporte

$17^{\circ}$ USIHC - Congresso Internacional de Ergonomia e Usabilidade de Interfaces Humano Computador

Keywords: design, ergonomics, usability, user satisfaction, fitness equipment.

\section{INTRODUÇÃO}

A população idosa no mundo está aumentando cada vez mais com o avanço da medicina e também as melhorias na qualidade de vida, desenvolvendo novas formas de minimizar e tratar doenças, contribuindo no aumento da longevidade. Para atingir melhoria na qualidade de vida, pode-se pensar em atividade física que, segundo Pereira e Rodrigues (2012), é essencial para a manutenção e preservação da capacidade funcional dos idosos, podendo mantê-los independentes em suas tarefas cotidianas durante toda a vida.

Além de trazer ganhos à saúde do corpo, a atividade física pode beneficiar a saúde mental, trazendo mais disposição, não apenas física, mas no bem-estar do indivíduo, confiança para as atividades diárias e para o relacionamento com as pessoas.

No entanto, para atingir tais objetivos é necessário a existência de espaços públicos ou privados que contemplem o público idoso juntamente com os demais públicos, envolvendo desde produtos de uso comum (equipamentos e mobiliário urbano) até sinalização, áreas verdes e espaços culturais. Recentemente, por volta de 2005, começaram a ser instaladas algumas academias de ginástica ao ar livre, quando o Ministério da Saúde lançou o programa Brasil saudável (FERNANDES, 2015), destinadas à prática de exercícios físicos, de uso coletivo e gratuito para a população. Os equipamentos contidos nessas academias são adquiridos por prefeituras ou empresas privadas e alocados em espaços públicos, como parques e praças.

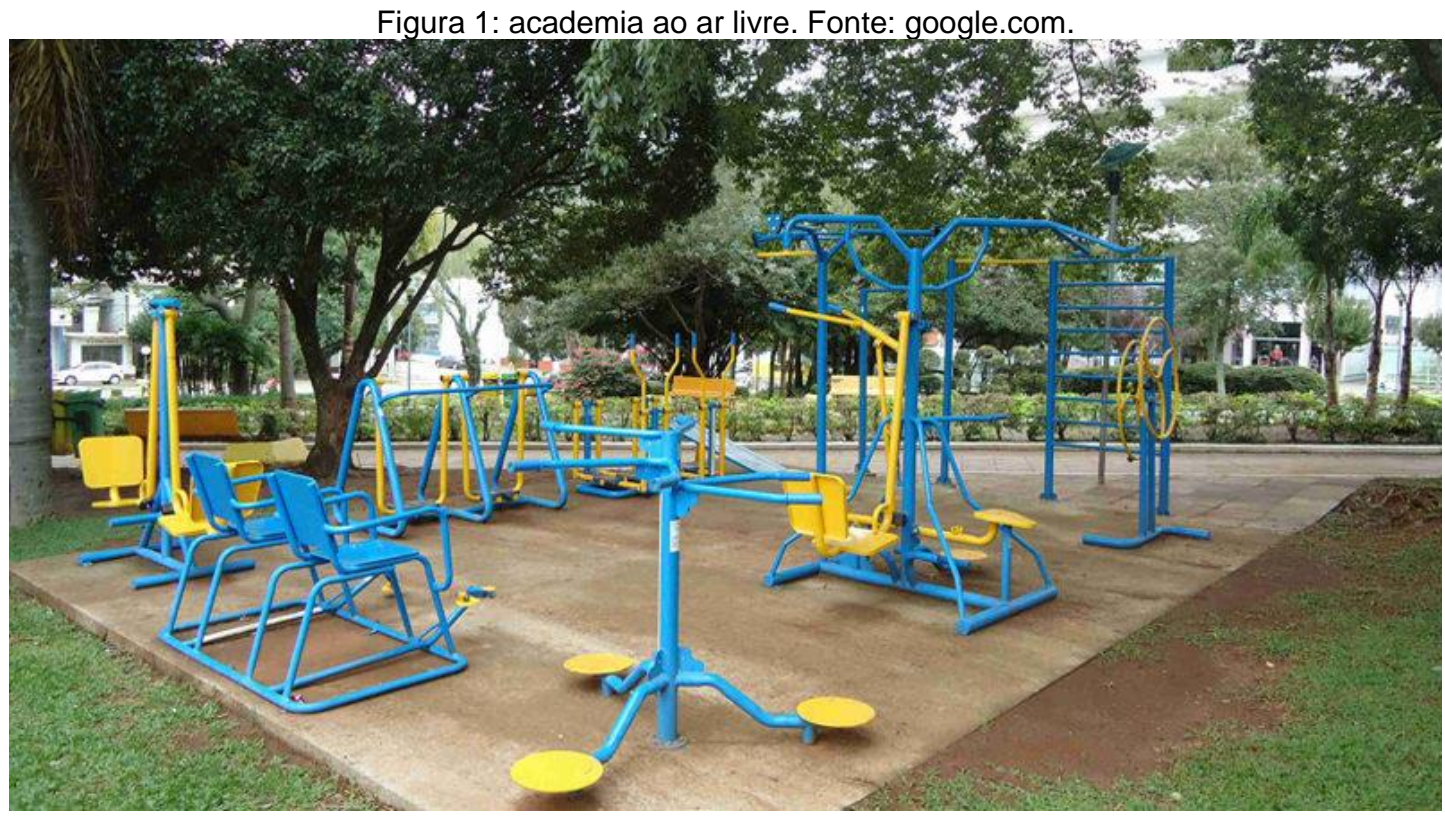

Essas academias ao ar livre têm surgido em diversas cidades brasileiras e também são chamadas de Academias da Terceira Idade ou ainda, Academias da Melhor Idade ou Academias da Saúde. Em Campina Grande, existem várias academias ao ar livre espalhadas 


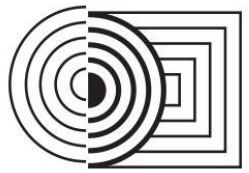

\section{$17^{\circ}$ ERGODESIGN \& USIHC 2019}

PUC-Rio, 11 a 13 de dezembro

Rio de Janeiro, RJ, Brasil $17^{\circ}$ Ergodesign - Congresso Internacional de Ergonomia e Usabilidade de Interfaces Humano Tecnológica: Produto, Informações Ambientes Construídos e Transporte

$17^{\circ}$ USIHC - Congresso Internacional de Ergonomia e Usabilidade de Interfaces Humano Computador

em diversos pontos da cidade.

Para a realização deste trabalho, optou-se por analisar os equipamentos da academia do Parque da Criança, uma vez que o local dispõe de uma maior estrutura para a prática de atividades físicas e de lazer, além de receber diariamente um grande fluxo de pessoas, com incidência considerável de idosos realizando atividades físicas, principalmente nos períodos matinais. O quadro 1 apresenta os equipamentos de ginástica da Academia ao ar livre do Parque da Criança.

Quadro 1: Equipamentos de ginástica da academia do Parque da Criança: (A) esqui, (B) simulador de caminhada, (C) simulador de cavalgada, (D) rotação dupla diagonal, $(E)$ pressão nas pernas, $(F)$ simulador de remo, $(G)$ rotação tripla vertical, $(\mathrm{H})$ multiexercitador, (I) surf duplo, (J) alongador triplo. Fonte: produzido pelo autor.

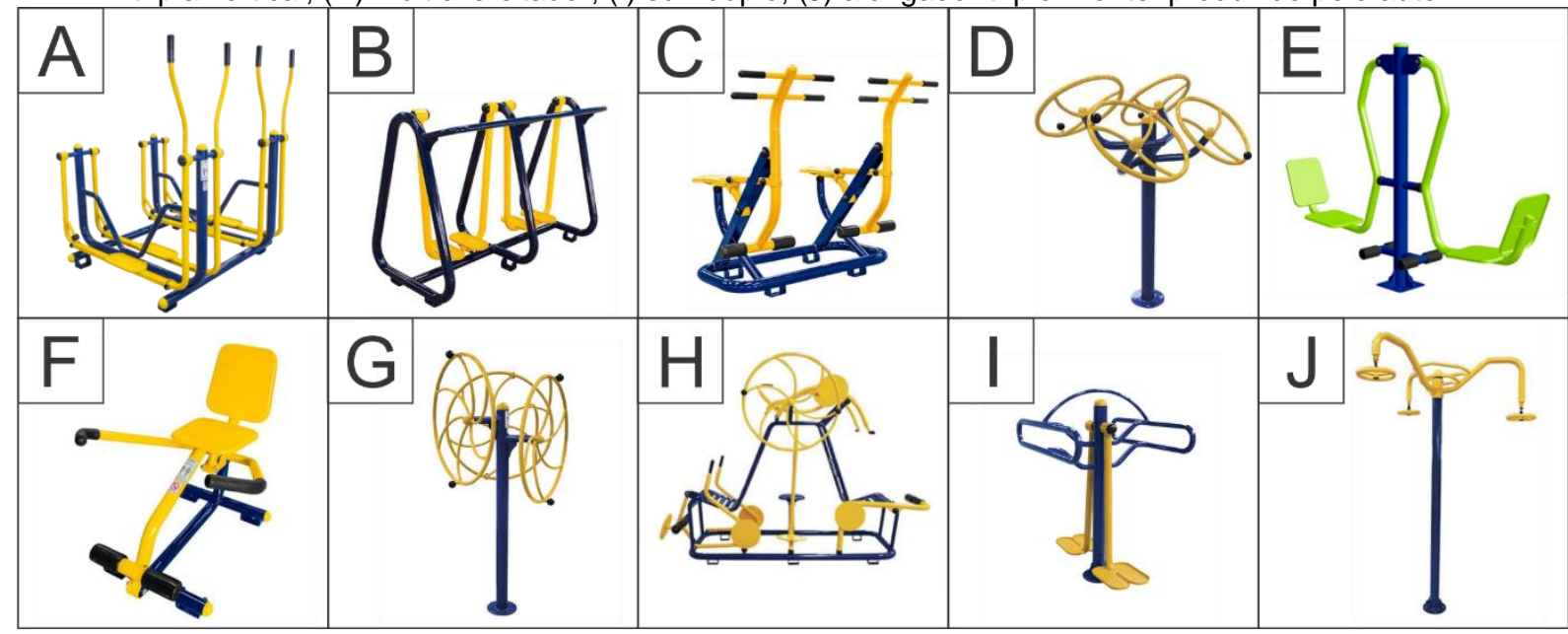

No local existem placas de instrução que indicam o modo de execução dos exercícios em cada equipamento, embora tenha-se percebido que muitos idosos utilizam o maquinário sem consulta-las, o que pode sugerir o uso de modo intuitivo. O problema de pesquisa que norteia o presente estudo é caracterizar o usuário da academia ao ar livre, e verificar sua satisfação sob uso dos equipamentos, considerando que foram concebidos com a proposta de uso equitativo.

\section{REFERENCIAL TEÓRICO}

\subsection{Público Idoso e Envelhecimento}

Tem crescido bastante o número de idosos que buscam melhorar sua qualidade de vida tornandose mais ativos, apesar das transformações biológicas, psicológicas e sociais, advindas das idades extremas e que afetam na "vida ativa" que, segundo Falzon (2007), são sinais do envelhecimento.

O processo natural de envelhecimento é, do ponto de vista biológico, fomentado por alterações moleculares e celulares, onde as células diminuem a sua capacidade de renovação, o que acaba resultando em perdas funcionais e progressivas dos órgãos e depois, de todo o organismo (FERNANDES, 2009).

É necessário se pensar em envelhecimento saudável, por isso o incentivo à promoção da saúde se torna algo importante. Podendo ser através de atividade física, caracterizando o 


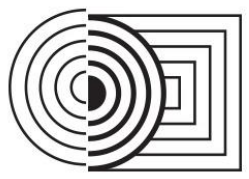

\section{$17^{\circ}$ ERGODESIGN \& USIHC 2019 \\ PUC-Rio, 11 a 13 de dezembro \\ Rio de Janeiro, RJ, Brasil}

$17^{\circ}$ Ergodesign - Congresso Internacional de Ergonomia e Usabilidade de Interfaces Humano Tecnológica: Produto, Informações Ambientes Construídos e Transporte

$17^{\circ}$ USIHC - Congresso Internacional de Ergonomia e Usabilidade

de Interfaces Humano Computador

"envelhecimento ativo", que segundo a OMS (2005, pag. 13), é o "processo de otimização das oportunidades de saúde, participação e segurança, com o objetivo de melhorar a qualidade de vida à medida que as pessoas ficam mais velhas".

Esse envelhecimento ativo pode vir a apresentar diversos efeitos benéficos ao organismo, como uma melhora no controle da obesidade, hipertensão arterial, diminuição nas taxas de diabetes, melhoria na composição corporal, diminuição de dores articulares, aumento da densidade óssea, aumento da capacidade aeróbia, melhora de força e de flexibilidade. Além dos benefícios físicos, a atividade física também proporciona benefícios psicossociais, como a melhoria na função cognitiva, alívio da depressão, aumento da autoestima e bem-estar individual (MENDES et al., 2016; FRANCHI, JUNIOR, 2005).

\subsection{Ergonomia e Usabilidade}

De acordo com a IEA (2018), a Ergonomia ajuda a harmonizar as coisas que interagem com as pessoas em termos de necessidades, habilidades e limitações das pessoas. A Associação Brasileira de Ergonomia (ABERGO, 2013), conceitua a Ergonomia como uma disciplina orientada para a abordagem sistêmica de todos os aspectos da atividade humana. E para Moraes e Mont'Alvão (2010), o principal objetivo da Ergonomia é melhorar as condições específicas do trabalho humano.

Vidal (2008), afirma que a Ergonomia vem para ajudar no desempenho das pessoas em suas atividades, trazendo mais segurança, conforto e eficácia para sua realização, através da modificação do processo de trabalho, adequando essa atividade as características, capacidades e limitações dos usuários.

Com a mesma linha de pensamento no que se refere à ação ergonômica, Veloso et. al. (2009) afirmam que, ela deve ser entendida como um conjunto de princípios e conceitos eficazes para viabilizar as mudanças necessárias para adequação do trabalho às características, habilidades e limitações dos trabalhadores, bem como dos produtos e sistemas, à luz dos critérios da saúde, segurança e efetividade.

Existem várias definições encontradas na literatura para o termo "Usabilidade", onde praticamente cada profissional da área traz a sua própria. Geralmente se tem alguns pontos em comum independentemente da definição a ser adotada, são eles: (1) um usuário envolvido; (2) que desenvolve alguma atividade; (3) utilizando um produto, sistema, ou alguma outra coisa (TULLIS, ALBERT, 2008).

Para Moraes (2001), a usabilidade refere-se à uma adequação entre o produto e as tarefas em que ele precisa desempenhar, ao usuário que irá utiliza-lo, e ao contexto em que será usado. Ela destacou então, a importância de adaptação dos produtos, o quão eles são adaptáveis a esses fatores. E reforçando, lida (2005), afirma que a usabilidade se refere à facilidade e a comodidade para o uso dos produtos, tanto no ambiente doméstico quanto no profissional. Ele afirma que os produtos devem ser fáceis de entender, de operar e pouco sensíveis a erros, eles devem ser "amigáveis".

Krug (2000), afirma que a usabilidade é caracterizada como a certeza de que alguma coisa funciona bem, uma pessoa com habilidade e experiência média (ou mesmo abaixo da média) 


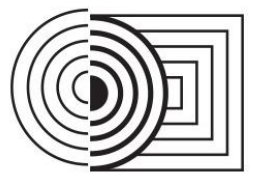

\section{$17^{\circ}$ ERGODESIGN \& USIHC 2019 \\ PUC-Rio, 11 a 13 de dezembro \\ Rio de Janeiro, RJ, Brasil}

pode usar alguma coisa, seja ela qual for e a que se destina, sem gerar frustração. Para o padrão ISO 9241-11 (2002) da NBR, usabilidade é a "medida em que um produto, serviço ou ambiente podem ser usados por usuários para alcançar objetivos específicos com eficácia, eficiência e satisfação em um contexto específico de uso". Nesta pesquisa, o recorte é da satisfação do usuário sobre o uso de equipamentos, área mais subjetiva da usabilidade.

\subsection{Percepção e Experiência do usuário}

Tornando-se uma questão de ponto inicial e foco de projeto, o design centrado no usuário obriga que a experiência dos usuários seja o objetivo principal, e todas as outras perspectivas sejam secundárias (KALBACH, 2009).

Segundo Cybis et. al (2010) a experiência do usuário surge com a interação entre o homem e a tecnologia, proporcionando uma visão abrangente entre as propriedades estéticas, funcionais e de interação com o produto da maneira que as pessoas respondem com aspectos físicos, emocionais e cognitivos.

Todo produto gera uma experiência para o usuário, sendo ela satisfatória ou não, quanto mais complexo é o produto, mais difícil é de ter sucesso na experiência do usuário (GARRET, 2011). A experiência do usuário então não se faz de maneira negligente, pois ela é o resultado do trabalho de profissionais diversos, que desempenham vários papéis que envolvem as questões de usabilidade, interação e contexto de uso (GUIMARÃES, SANTOS, FONTANA, 2017).

Para Tullis et al. (2008), é possível medir a experiência do usuário a partir de métricas de usabilidade, como por exemplo, número de tentativas, tempo de resposta, tempo de realização de tarefas, quantidade de erros, entre outras coisas. Entretanto, os autores destacam que existe diferença entre os termos usabilidade e experiência do usuário.

O sistema tem que ser útil para o usuário, apresentar uma boa usabilidade através de uma interação adequada. Uma boa experiência do usuário (UX) pressupõe que o sistema seja fácil de usar, que tenha credibilidade. O usuário deve sentir o desejo de usar o sistema, que deve ser acessível e que propicie valor, de maneira que essa experiência ao usar o sistema, seja agradável e produtiva (GUIMARÃES, 2008).

\subsection{Produtos de Uso Coletivo e Equipamentos Urbanos}

A classificação dos produtos segue geralmente uma premissa da destinação de seu uso. De acordo com o tipo de relações existentes entre o usuário e o produto, Löbach (2001), destaca as seguintes categorias: (1) produtos de consumo (deixam de existir após o uso), (2) produtos de uso 1: uso individual, (3) produtos de uso 2: uso de determinados grupos, (4) produtos de uso 3 : uso indireto.

A abordagem desta pesquisa é sobre os "produtos de uso 2: uso de determinados grupos" ou, produtos de uso coletivo. Geralmente esses produtos são concebidos para atender necessidades, muitas vezes indispensáveis, de um maior número de pessoas em comparação com produtos de uso individual (PIZZATO, 2013).

Esses produtos são utilizados por um grupo pequeno de pessoas que se conhecem, porém, 
podendo se ampliar o grupo, a um grande grupo de pessoas que não se conhecem. Então, é necessário considerar as necessidades gerais do grupo no processo de projeto, de forma que 0 resultado "agrade" a maioria dos usuários (LÖBACH, 2001).

Os equipamentos de ginástica ao ar livre são equipamentos de uso coletivo, e também são considerados equipamentos urbanos que, segundo a Associação Brasileira de Normas Técnicas (ABNT), são todos os bens públicos e privados, de utilidade pública, destinados à prestação de serviços necessários ao funcionamento da cidade, implantados mediante autorização do poder público, em espaços públicos e privados.

Portanto, esse estudo tratará como equipamentos de ginástica, todos esses produtos/sistemas utilizados na prática de atividades físicas por parte da população na academia ao ar livre do Parque da Criança.

\section{METODOLOGIA}

Este artigo se refere ao recorte de uma dissertação em andamento (Programa de Pós-graduação em Design), que corresponde à sua fase de exploração, onde foi realizado um teste piloto com usuários. O público alvo são os idosos que frequentam a academia ao ar livre do Parque da Criança, localizada em Campina Grande - PB. O objeto do estudo é o grupo de equipamentos que integram essa academia ao ar livre.

O artigo tem como objetivo caracterizar o usuário idoso, bem como verificar sua satisfação sob o uso dos equipamentos. O teste piloto foi realizado através de observação e aplicação de formulário em dias aleatórios durante os meses de Janeiro e Fevereiro de 2019, nos turnos da manhã e da tarde, tendo sido divido em duas partes.

A primeira parte identificou seu perfil social, para assim caracteriza-lo, contendo questões como: sexo, data de nascimento, estado civil, alfabetismo e formação, ocupação, frequência de prática de atividade física, além do turno preferencial para sua prática.

A segunda parte foi destinada à satisfação do usuário sob o uso dos equipamentos, com questões a respeito de preferências e tendências de usabilidade, como exemplo: equipamentos preferenciais e rejeitados, causas de rejeição, nível de satisfação e dificuldade, forma de uso e segurança dos equipamentos.

Os resultados desse processo serão apresentados com detalhes no item 4.

\section{RESULTADOS E DISCURÇÕES}

Com o objetivo de caracterizar os usuários, através de seu perfil social, observa-se que, dentre os entrevistados que participaram do teste, $60 \%$ são do sexo feminino e $40 \%$ do sexo masculino, todos alfabetizados.

Quanto ao grau de instrução, apenas $10 \%$ possui ensino fundamental incompleto, $10 \%$ possui o fundamental completo, $40 \%$ possui o ensino médio completo, $10 \%$ possui o ensino superior incompleto e $30 \%$ possui Pós-graduação (gráfico 1). Esses dados mostram-se importantes por 
conta da leitura e compreensão das placas instaladas nas academias, que tem a função de nomear os equipamentos e ensinar a forma correta de execução dos exercícios em cada um deles.

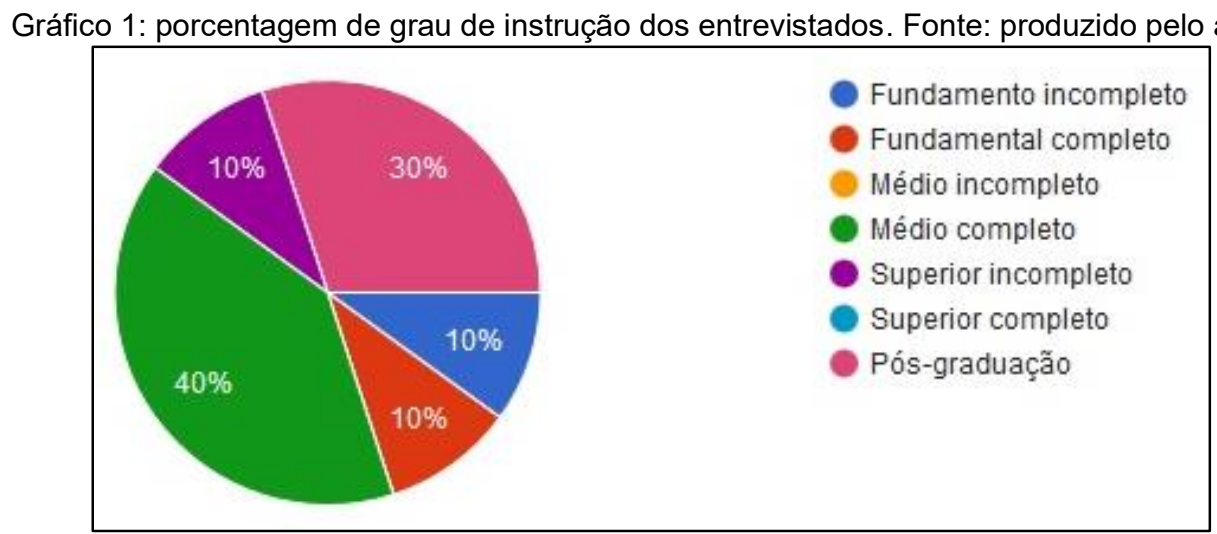

As entrevistas mostraram também que boa parte dos usuários ( $80 \%)$ já são aposentados. Destes, $100 \%$ praticam atividades físicas periodicamente, ou seja, são idosos ativos. Quanto ao período que frequentam os parques para realização de atividades físicas, houve maior predominância no turno da manhã ( $80 \%)$. Os demais realizam as atividades em turnos alternados.

Para verificar a satisfação dos usuários, através de preferências e tendências de usabilidade, além da aplicação do formulário foram feitas observações in loco. Os dados apontaram os equipamentos mais utilizados e, numa escala do maior para o menor, estão: $\left(1^{\circ}\right)$ esqui, $\left(2^{\circ}\right)$ simulador de caminhada, $\left(3^{\circ}\right)$ rotação dupla diagonal, $\left(4^{\circ}\right)$ pressão nas pernas, $\left(5^{\circ}\right)$ surf duplo, $\left(6^{\circ}\right)$ simulador de cavalgada, $\left(7^{\circ}\right)$ simulador de remo, $\left(8^{\circ}\right)$ multiexercitador, $\left(9^{\circ}\right)$ alongador triplo e $\left(10^{\circ}\right)$ rotação tripla vertical (Quadro 1).

Os motivos apontados para o menor uso dos três últimos equipamentos foram: afinidade $(37,5 \%)$; desconforto (25\%); possuir algum problema físico que o impede ou dificulte realizar tal exercício $(25 \%)$ e dificuldade no uso $(12,5)$ (Gráfico 2$)$.

Gráfico 2: Motivos da rejeição de equipamentos pelos usuários. Fonte: produzido pelo autor.

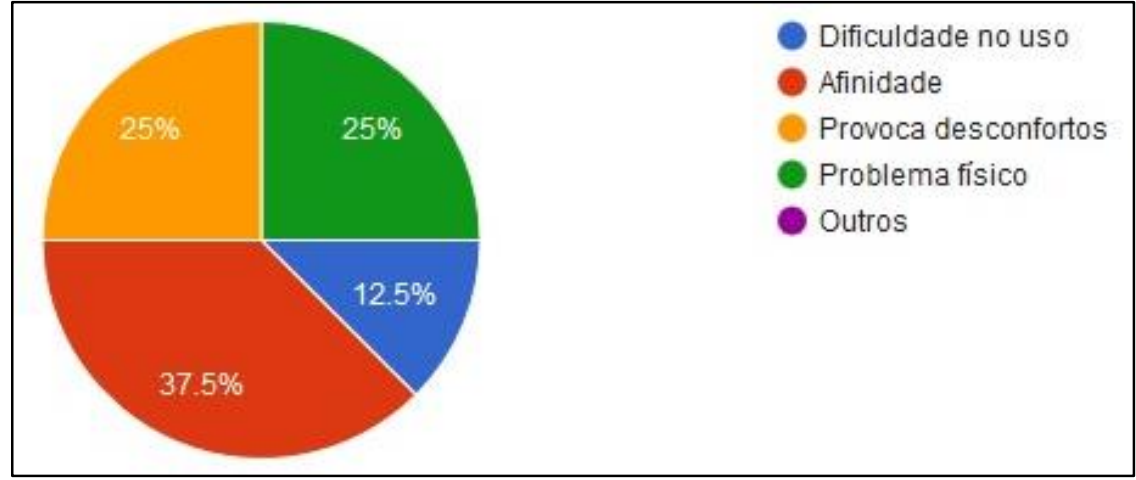

Já considerando o grau de satisfação dos usuários sob o uso dos equipamentos, tem-se um resultado de $100 \%$ de aceitação, todos os entrevistados apontaram como positiva a sua 
experiência de uso.

Sobre o conhecimento adquirido para utilizar os equipamentos, 30\% afirmaram usar intuitivamente, 30\% afirmaram ter conhecimento (empírico), 30\% afirmaram que aprenderam por observação de outros usuários executando os exercícios e apenas $10 \%$ afirmaram que leem a placa de sinalização dos equipamentos (Gráfico 3).

Gráfico 3: maneira de uso dos equipamentos. Fonte: produzido pelo autor.

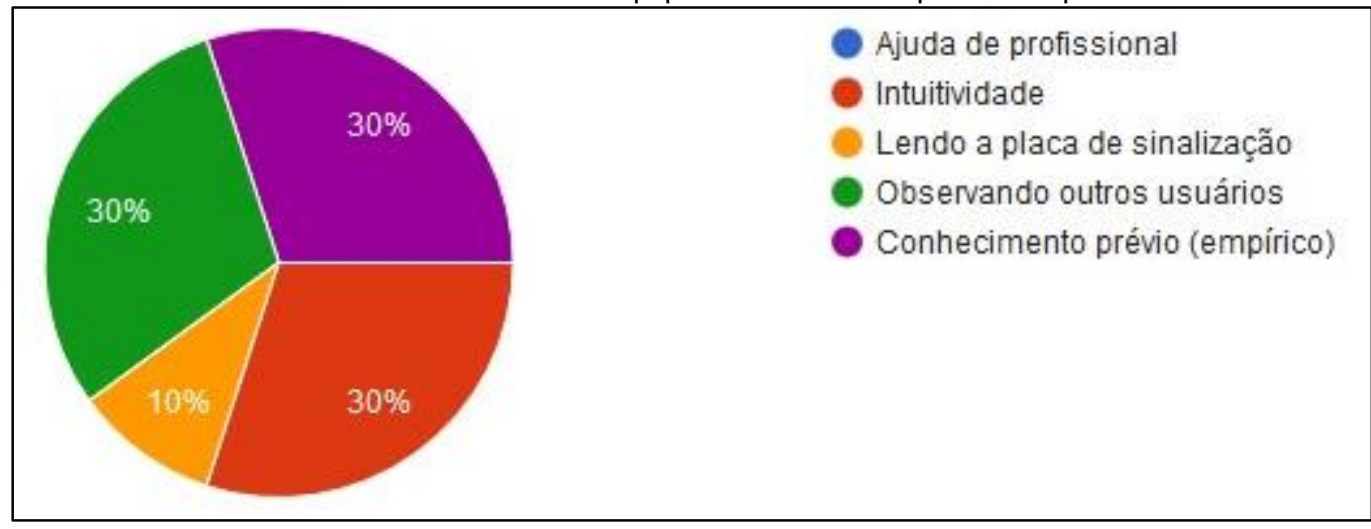

Quanto à segurança dos equipamentos, $90 \%$ responderam sentir-se seguros e nenhum deles sofreu qualquer tipo de lesão física proveniente do uso desses equipamentos.

Considerando o grau de dificuldade na realização dos exercícios, os entrevistados foram questionados a esse respeito para cada um dos equipamentos. A maioria das respostas apontou fácil uso e execução, porém os equipamentos: (1) simulador de remo, (2) rotação tripla vertical, (3) multiexercitador e (4) alongador triplo foram apontados como difíceis por alguns usuários. Esta informação corrobora com o fato de terem sido apontados anteriormente como os menos utilizados. As observações permitiram também, verificar que os usuários podem adotar formas diferenciadas e ou/inesperadas de utilizar os equipamentos, como apresentado na Figura 2.

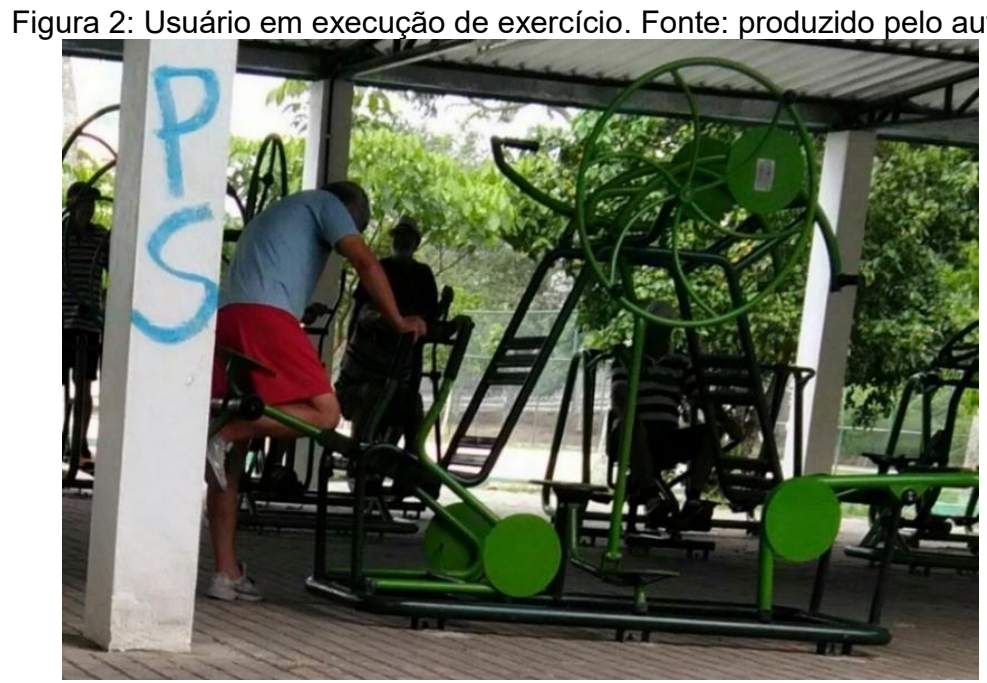


$17^{\circ}$ ERGODESIGN \& USIHC 2019

PUC-Rio, 11 a 13 de dezembro

Rio de Janeiro, RJ, Brasil $17^{\circ}$ Ergodesign - Congresso Internacional de Ergonomia e Usabilidade de Interfaces Humano Tecnológica: Produto, Informações Ambientes Construídos e Transporte

$17^{\circ}$ USIHC - Congresso Internacional de Ergonomia e Usabilidade de Interfaces Humano Computador

O equipamento exposto na figura 2 é o Multiexercitador, e observa-se que a execução do exercício está sendo realizada de maneira distinta da prescrita pela placa indicativa (Figura 3).

Figura 3: Placa indicativa Multiexercitador. Fonte: produzido pelo autor.

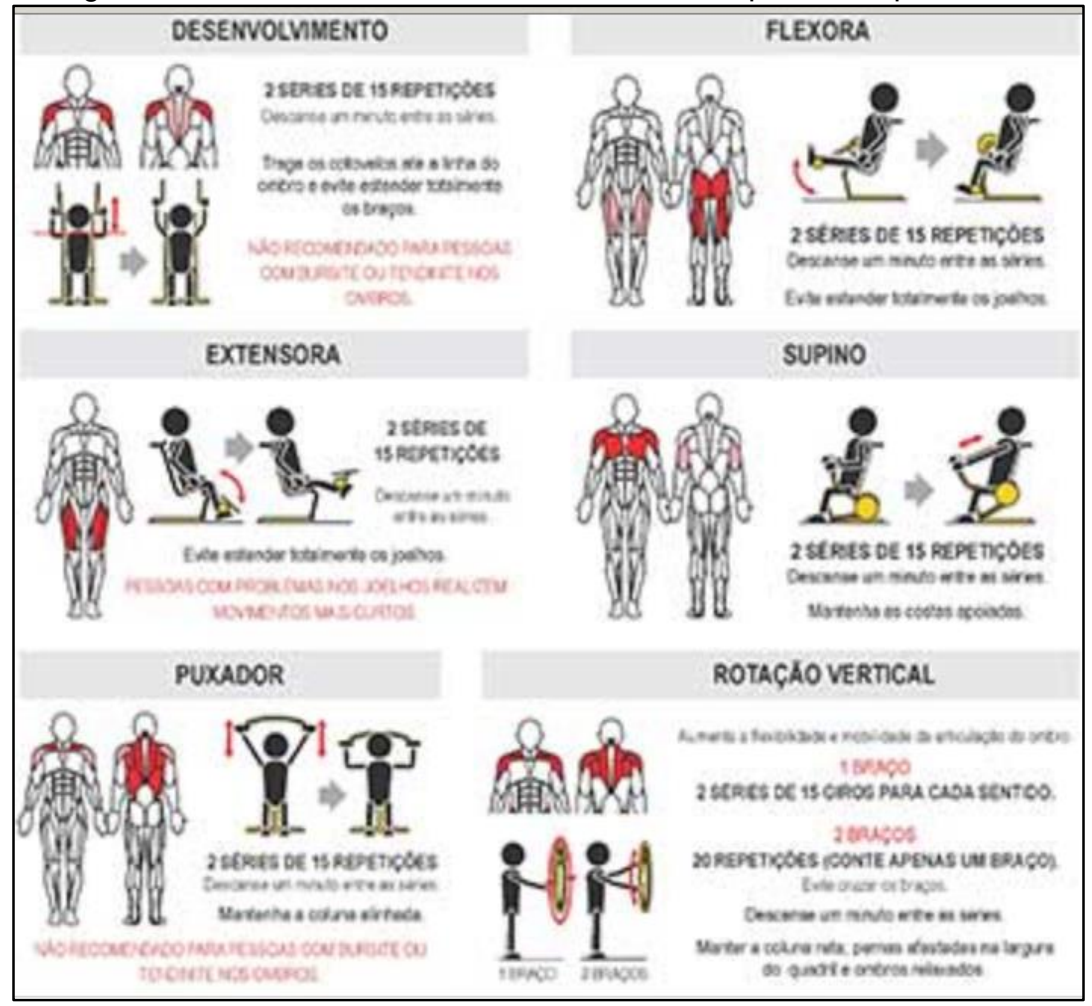

\section{CONCLUSÕES}

Considerando a escolaridade e formação dos entrevistados, nota-se que são capazes de ler as placas de indicação instaladas na academia ao ar livre, porém ainda existe certa resistência em utiliza-las. Tendo em vista o número de aposentados, percebe-se que grande parte dos idosos tem mais tempo livre, e por isso podem usufruir desses locais com mais frequência, principalmente durante o turno matinal, conforme responderam os entrevistados.

Sobre os equipamentos, há preferências por alguns deles, principalmente por questões de afinidade, conforto, além de que, alguns usuários relataram já possuírem problemas físicos. De forma geral foram considerados fáceis de usar, apesar de alguns usuários sentirem um pouco de dificuldade com um ou outro equipamento específico.

A satisfação dos usuários é totalmente positiva quanto ao uso dos equipamentos, os entrevistados atestam que eles são intuitivos, além de que, em casos mais extremos de necessidade, se ajudam uns aos outros na hora dos exercícios. Outro fator que corrobora na satisfação positiva é a segurança dos equipamentos, todos os usuários sentem-se seguros e 
confiantes ao utiliza-los.

Outro ponto a se considerar são algumas tendências de usabilidade dos usuários, como algumas vezes realizarem atividades de forma diferente do que é indicado nas placas, assumindo algumas posturas inadequadas. O que seria o caso de se pensar na manutenção de um profissional da área de educação física atuando nesses locais.

Os equipamentos mostraram ser fáceis de usar, considerando os movimentos prescritos para realização do exercício, e também que não há dificuldades quanto à sua intensidade, pois eles não têm carga, a não ser o peso do próprio indivíduo, e em alguns a atividade é apenas de alongamento. Em média, os equipamentos têm alta aceitação dos usuários, pois são bastante intuitivos quanto ao uso.

\section{REFERÊNCIAS BIBLIOGRÁFICAS}

ABERGO. Norma ERG BR 1002 - Código de Deontologia do Ergonomista Certificado. Disponível em: <http://www.abergo.org.br/arquivos/normas_ergbr/norma_erg_br_1002_deontologia.pdf> Acesso em 02 Agosto 2018.

ASSOCIAÇÃO BRASILEIRA DE NORMAS TÉCNICAS. NBR 9050: Acessibilidade a edificações, mobiliário, espaços e equipamentos urbanos. Rio de Janeiro, 2015. 162 p.

ASSOCIAÇÃO BRASILEIRA DE NORMAS TÉCNICAS. NBR 6028: RESUMOS. Rio de Janeiro, 2003. 3p.

CYBIS, Walter de Abreu; BETIOL, Adriana Holtz; FAUST, Richard. Ergonomia e Usabilidade: conhecimentos, métodos e aplicações. São Paulo: Novatec, 2010.

FALZON, Pierre (org.). Ergonomia. $1^{\circ}$ edição. São Paulo - SP: Blucher, 2007. Cap. 1, p. 3-19.

FALZON, Pierre (org.). Ergonomia. $1^{\circ}$ edição. São Paulo - SP: Blucher, 2007. Cap. 9, p. 111123.

FALZON, Pierre (org.). Ergonomia. $1^{\circ}$ edição. São Paulo - SP: Blucher, 2007. Cap. 28, p. 393405.

FERNANDES, Brunno De Pieri. Motivação para a prática de exercícios físicos em academias ao ar livre em praças públicas. 2015. 76f. Trabalho de Conclusão de Curso (Graduação em Educação Física) - Faculdade de Educação Física. Universidade Estadual de Campinas, Campinas, 2015.

FERNANDES, Júlio Cesar Felix de Alencar. Abordagem da Ergonomia para a análise da acessibilidade de uma instituição de longa permanência para idosos da cidade de NatalRN. 2009. 213 fs. Dissertação de Mestrado submetida ao Programa de Engenharia de Produção - Universidade Federal do Rio Grande do Norte. Natal-RN.

FRANCHI, Kristiane Mesquita Barros; JUNIOR, Renan Magalhães Montenegro. ATIVIDADE FÍSICA: UMA NECESSIDADE PARA A BOA SAÚDE NA TERCEIRA IDADE. In: Revista Brasileira em Promoção da Saúde. V. 18, N.3, 2005.

MENDES, B. et al. Associação de fatores de risco para doenças cardiovasculares em adolescentes e seus pais. In: Revista Brasileira de Saúde Materna Infantil. V.6, supl. 1, Recife, maio, 2016. 


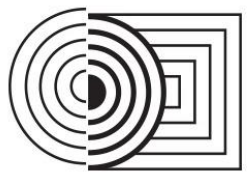

\section{$17^{\circ}$ ERGODESIGN \& USIHC 2019 \\ PUC-Rio, 11 a 13 de dezembro \\ Rio de Janeiro, RJ, Brasil}

GARRETT, Jesse James. The Elements of User Experience: user-centered design for the web and beyond. 2. Ed. Berkley: New Riders, 2011.

GUIMARÃES, C. A Usabilidade no dia-a-dia - a interação de seres humanos com sistemas. Belo Horizonte: Fundac-bh. 2008

GUIMARÃES, Cayley; SANTOS, Leandro Augusto F; FONTANA, Isabela M. Design \& Engenharia de Usabilidade - aplicação pratica na criação de um aplicativo. Design \& Tecnologia. Porto Alegre - RS, v. 7, n. 14, p. 11-29, dezembro, 2017.

IEA, International Ergonomic Association. Definição e Domínios da Ergonomia. Disponível em $<$ https://www.iea.cc/whats/index.html >. Acesso em 04 de Setembro de 2018.

IIDA, I. Ergonomia: Projeto e Produção. São Paulo: Edgard Blücher, 2005.

ISO 9241. Requisitos Ergonômicos para Trabalho de Escritórios com Computadores. Parte 11: Orientações sobre Usabilidade, 2002.

KALBACH, James. Design de Navegação Web: otimizando a experiencia do usuário. 1. ed. Porto Alegre - RS: ARTMED EDITORA S.A. 2009.

Krug, Steve. 2000. Don't make me think! A common sense approach to web usability. IndianaPolis: New Riders Press.

LÖBACH, B. Design Industrial - Bases para a configuração dos produtos industriais. 1. ed. São Paulo: Edgard Blücher, 2001.

MORAES, Anamaria de; MONT'ALVÃO, Claudia. Ergonomia: conceitos e aplicações. $4^{\circ}$. ed. Ed. 2AB: Rio de Janeiro, 2010. 224 p.

MORAES, A. D. Ergonomia e usabilidade de produtos, programas, informação: área de concentração, linhas de pesquisa, projetos de pesquisa, ideias, realizações, produção e competências. In: MORAES, A. D.; FRISONI, B. C. Ergodesign: produtos e processos. Rio de Janeiro: 2AB, 2001. p. 9-50.

ORGANIZAÇÃO MUNDIAL DA SAÚDE. Envelhecimento ativo: uma política de saúde / World Health Organization; tradução Suzana Gontijo. - Brasília: Organização Pan-Americana da Saúde, 2005.

PEREIRA, Maria Angélica Leite; RODRIGUES, Minéia Carvalho. Perfil da capacidade funcional em idosos residentes no condomínio Vila Vida em Jataí-GO. Rev Bras Ativ Fis Saúde, Florianópolis, v. 12 n. 1, pp. 27-33, setembro 2012.

PIZZATO, Gabriela Zubaran de Azevedo. Design e emoção na utilização do mobiliário urbano em espaços públicos. 2013. 159 f. Tese (Doutorado em Engenharia) - Escola de Engenharia, Universidade Federal do Rio Grande do Sul, Porto Alegre, 2013.

TULLIS, Thomas; ALBERT, Willian. Measuring the user experience: collecting, analyzing, and presenting usability metrics. Burlington: Morgan Kaufman, 2008.

VELOSO, Isis Tatiane de Barros Macedo; OLIVEIRA, Larissa Praça; JAESCHKE, Anelena; CELESTINO, Joyce Elanne Mateus; SALDANHA, Maria Christine Werba. Instrução da Demanda ergonômica como ferramenta para o design de produtos: um estudo de caso na atividade jangadeira. In $9^{\circ}$ ERGODESIGN, Curitiba, 2009.

VIDAL, Mário César Rodriguez. Guia para análise ergonômica do trabalho (AET) na empresa. $2^{\circ}$. Ed. Virtual Científica: Rio de Janeiro, 2008. 332 p. 